\title{
O neopentecostalismo e os dilemas da modernidade periférica sob o signo do novo desenvolvimentismo brasileiro
}

Neopentecostalism and the dilemmas of peripheral modernity under the sign of the Brazilian new developmentalism

\section{Capitalismo, ação política e democracia num contexto de modernidade periférica}

Vivemos sob a égide de uma crise da política, de seu modus faciendi tributário da tradição moderna, contratualista e liberal, cuja essência fez germinar o Estado moderno e, no dizer de Benedict Anderson, as comunidades imaginadas, ou seja, as nações constituídas com base num longo processo histórico de unificação política, territorial, econômica e linguística. Do encontro entre nação e Estado - obra e arte da Revolução Francesa -, surgiu a república moderna e com ela o evolver da cidadania até conquistas civilizatórias como a extensão universal do sufrágio e dos direitos sociais. Daí em diante, assentou-se o entendimento de que, com esse arcabouço institucional, viria a se consolidar um modelo normativo de democracia caracterizado por partidos burocrático-formais, devotados à representação fiduciária dos interesses que os elegeram e subsumidos em uma dinâmica eleitoral cíclica que os constrangeria inexoravelmente a um processo permanente de alternância de poder e renovação de elites - o que garantiria, por seu turno, o hígido equilíbrio na representação dos interesses sociais que orbitam a esfera da política (Manin, 1997; Urbinati, 2006).

\footnotetext{
Doutorando em Ciência Política, na UFSCar (São Carlos, SP, Brasil) e membro do Laboratório de Política e Governo da Unesp (Labpol). E-mail: gantonio86@hotmail.com.

** Professor do Programa de Pós-Graduação em Ciências Sociais da UNESP (Araraquara, SP, Brasil) e do Programa de Pós-Graduação em Ciência Política da UFSCar (São Carlos, SP, Brasil). Coordenador do Laboratório de Política e Governo da Unesp (Labpol). E-mail: lahuerta@fclar.unesp.br.
} 
Acontece que, simultaneamente ao desenvolvimento de democracias partidárias competitivas no Ocidente, foram sendo diluídos também os condicionantes da vida gregária e associativa que haviam permitido a institucionalização do conflito social em bases político-partidárias, ou ainda, nos moldes da tradicional polarização direita-esquerda, capital-trabalho (Offe, 1984). Isso se deve, sobretudo, à emergência de um novo padrão produtivo e tecnológico engendrado a partir da década de 1970, que abalou a primazia dos Estados nacionais na condução de políticas de planejamento social, econômico e industrial, na medida em que o esteio primevo da geração de riqueza deixou de ser o regime de produção fordista e passou a ser a chamada "acumulação flexível”. Em virtude do aprimoramento da informática, que com a internet possibilita a comunicação remota em tempo real, a informação sobre a riqueza e o dinheiro se autonomizou de sua base material, passando a circular livremente de um mercado a outro, integrando globalmente a economia e gerando um processo de "financeirização" da riqueza, sem que os países e seus respectivos governos tivessem instrumentos plenamente capazes de lidar com o surgimento e a aceleração de toda uma cadeia de fluxos (de pessoas, serviços, informações, mercadorias, crises etc.) gerados a reboque disso.

Do ponto de vista da política, tal processo trouxe duas grandes consequências: 1) a celeridade da dinâmica econômico-informacional demanda a aceleração das respostas institucionais, cobrando da política um padrão de rapideze eficiência decisória estranho à liturgia e aos procedimentos deliberativos típicos da atividade parlamentar; 2) a integração tecnológica via satélite, mormente após a mundialização da internet, radicaliza a experiência - engendrada pela moderna economia política capitalista dos séculos XVIII e XIX - de diluição das fronteiras entre o concreto e o abstrato, recondicionando a existência empírica dos sujeitos para além dos limites geográfico-culturais, de sorte a produzir tensões inarredáveis entre os padrões institucionalizados de reprodução social e as formas emergentes (cosmopolitas e/ou globais) de organização da cultura (Avritzer, 2002); como corolário, potencializam-se movimentações político-sociais de cunho fundamentalista ou conservador, muitas delas com forte conotação religiosa, reativas a esses processos de desencaixe ${ }^{1}$ da alta modernidade. Por outro lado, emerge também aquilo que Ulrick Beck chama de

De acordo com Anthony Giddens (2002, p. 221), desencaixe é o processo através do qual ocorre o descolamento das relações sociais dos contextos locais e sua recombinação através de distâncias indeterminadas do espaço-tempo. 
subpolítica (subpolitics) $)^{2}$, ou seja, a penetração de agentes externos ao sistema político no cenário do planejamento social, o que implica uma mudança quantitativamente exponencial e qualitativamente expressiva de demandas relacionadas à preservação do meio ambiente e à melhoria dos padrões de bem-estar, consumo, comportamento, estilos de vida, valores etc., culminando, de maneira abrangente, em transformações no modo e na intensidade como as sociedades passam a negociar alterações em suas próprias estruturas normativas e de poder.

Deslinda-se, nesse cenário, um novo tipo modelar de sujeito político, para o qual o território da política institucional torna-se incipiente face à multiplicação de estímulos que o compelem a (re)agir constantemente às consequências, cada vez mais pessoais (biográficas), dos processos acima enunciados. Uma dessas consequências é a deslegitimação dos “políticos profissionais" e de seus anteparos burocráticos, quais sejam, os partidos e as demais instâncias representativas subsidiárias (associações sindicais, corporativas e demais agências ligadas à órbita dos interesses na esfera do mercado capitalista). Assim sendo, como hierarquizar prioridades, identificar tendências, organizar demandas, construir consensos sociais mais amplos e consubstanciá-los em valores políticos nessa plêiade de indivíduos que, para além da clássica disjuntiva ideológica de classe, associam-se, desvinculam-se ou recombinam-se no interior de movimentos de forma absolutamente imprevisível, por vezes efêmera, mas com uma intensidade e frequência cada vez maiores no Brasil e no mundo? Onde localizar centros políticos ordenadores dessa multidão que se organiza em rede, de maneira horizontal, multicêntrica, referenciada muitas vezes pelo senso-comum predominante nos ambientes sociais domésticos, nas redes sociais da internet e nos meios de comunicação de massa?

Para tornar ainda mais complexo o cenário em tela, urge destacar que, tanto no Brasil como no resto da América Latina, a modernidade engendrada é caudatária das transformações econômicas e científico-tecnológicas produzidas alhures, nos polos dinâmicos da acumulação de capital ${ }^{3}$. Isso significa que essas

Nas palavras de Ulrich Beck, "a subpolítica (sub-politics) distingue-se da'política'porque se permite que os agentes externos ao sistema político ou corporativo apareçam no cenário do planejamento social (...), e, em segundo, porque não somente os agentes sociais e coletivos, mas também os indivíduos, competem com este último e um com o outro pelo poder de conformação emergente do político" (Beck, 1995, p. 34).

Vale lembrar a existência de um extenso e profícuo debate, produzido pela sociologia política brasileira dos anos 1960-70, que tratou das afinidades eletivas entre desenvolvimento dependente e marginalização social no contexto latino-americano. O centro desse debate esteve, sem dúvida, na chamada teoria da dependência, em cujo eixo estava a clássica obra Dependência e desenvo/vimento 
sociedades experimentam, atualmente, a conjugação de problemas associados, respectivamente, a pelo menos duas temporalidades distintas (Lahuerta, 2003). O primeiro rol de problemas refere-se à persistente condição, por parte das populações subalternizadas, de ampla miséria e escasso acesso a direitos ${ }^{4}$, cuja superação, no plano histórico, esteve consubstanciada ao desenvolvimento econômico-industrial dos países centrais do capitalismo, os quais, através de distintos níveis de regulação keynesiana, instituíram uma política de compromisso de classes capaz de promover um patamar de cidadania que ampliou significativamente os serviços sociais prestados pelo Estado, gerando, nos dizeres de T. H. Marshall, um “(...) enriquecimento geral da substância concreta da vida civilizada, a redução geral do risco e insegurança [e] uma igualação entre os mais e menos favorecidos em todos os níveis" (Marshall, 1967, p. 94).

O segundo rol de problemas está atrelado ao momento hodierno do capitalismo, sobretudo ao desenvolvimento dos sistemas de produção flexível e de um mercado financeiro global, que reduziram drasticamente o tempo de giro da produção e do capital como um todo, implicando uma reestruturação completa do trabalho - cada vez menos fabril e mais concentrado no chamado setor de serviços -, além de mudanças sensíveis nos padrões de consumo e estilos de vida, tornando-os mais consentâneos “(...) a uma estética pós-moderna que celebra a diferença, a efemeridade, o espetáculo, a moda e a mercadificação de formas culturais" (Harvey, 2007, p. 148). Um dos corolários dessa revolução material e simbólica do novo capitalismo, no caso especificamente brasileiro, é a potencialização de um tipo de empreendedorismo que sempre foi forte nas camadas subalternas, mas que agora adquiriu a condição de fenômeno de massa (Lahuerta, 2001). A um ponto

na América Latina, de Fernando Henrique Cardoso e Enzo Faletto. A contraparte desse debate pode ser localizada na obra Subdesarrollo y revolución, de Ruy Mauro Marini. Grosso modo, tal debate foi responsável pela identificação de duas vias distintas - reformismo, no primeiro caso; revolução, no segundo - para a superação do atraso econômico e do subdesenvolvimento latino-americano (Kowarick, 2009; Lahuerta, 1999).

4 Nesse aspecto, Wanderley Guilherme dos Santos chama a atenção para a aviltante insuficiência da cobertura legal e jurídica do Estado brasileiro, cujo resultado é um grau extremo de retração da esfera pública, produzindo uma situação de hobbesianismo social (Santos, 1992,1993). Ainda segundo o autor,"(...) sabe-se que a capacidade operacional do Estado também é diferente, nas áreas de há muito incorporadas ao complexo nacional, conforme distribuição social das populações. Nos morros e periferias das grandes cidades, é cadente a eficácia do Estado em fazer cumprir as suas leis. Processo que vem se agigantando desde décadas, atingiu o máximo ao demolir a vigência dos valores constitucionais básicos - os direitos de ir e vir, de opinião e de organização -, substituindo-os pelo exercício extemporâneo de um conjunto de leis e executores sob jurisdição do crime organizado. O Estado brasileiro que, neste aspecto, sempre foi frágil, tornou-se esquálido. As consequências não são de pouca monta" (Santos, 2005, p. 23). 
isso vem ocorrendo que vários pesquisadores têm tratado o problema a partir da ideia de que teria surgido uma nova classe média no país (Neri, 2010; Singer, 2009; Souza, 2012). Dentre eles, cabe destacar a contribuição de Jesse Souza, que qualifica essa emergência recorrendo à ideia de afirmação de uma classe social de novo tipo, chamada por ele de batalhadores. Segundo esse autor, a modernização brasileira não constituiu apenas as novas classes sociais modernas que se apropriam diferencialmente dos capitais cultural e econômico, mas também “(...) uma classe inteira de indivíduos não só sem capital cultural nem econômico em qualquer medida significativa, mas desprovida, esse é o aspecto fundamental, das precondições sociais, morais e culturais que permitem essa apropriação" (Souza, 2012, p. 25).

Ainda segundo Souza, os batalhadores não seriam tipos ideais de trabalhadores flexíveis cujo acesso a um conhecimento específico lhes garantiria uma fatia de mercado nesse mundo em mudança.

Ao contrário, a regra parece ser a utilização de qualquer princípio econômico que permita sobrevivência e sucesso num mercado altamente competitivo. Assim, encontramos pequenas oficinas de produção onde o trabalho era controlado segundo princípios fordistas. Em outros tipos de trabalho, as relações familiares de favor e proteção substituíam as relações impessoais para prejuízo dos trabalhadores que tinham jornada alongada de trabalho sem poder reclamar do tio que havia lhe "dado" emprego (Souza, 2012, p. 56).

Essa "nova classe social", formada por aproximadamente 16 milhões de famílias que ascenderam aos mercados de trabalho e consumo modernos por conta das políticas sociais e da elevação do salário-mínimo que as habilitou ao crédito (Neri, 2010; Belluzzo, 2013), corporifica, no plano político, o surgimento de uma clivagem que, não obstante sua gratidão eleitoral ao ex-presidente Lula e à sua sucessora Dilma Rousseff - próceres do bloco de poder que sustentou tal incorporação social -, não sinaliza para uma clara identificação ideológica com nenhuma das classes fundamentais do capitalismo, permanecendo atrelada ao pacto reformista do qual é tributária, sem, no entanto, dele participar de maneira autônoma e destacada, dada a dificuldade de construir suas próprias formas de organização ${ }^{5}$.

Segundo André Singer, "o pulo do gato de Lula foi, sob o pano de fundo da ortodoxia econômica, construir uma substância política de promoção do mercado interno voltado aos menos favorecidos, 
A ausência de autonomia política e de claros posicionamentos ideológicos leva a que essa parcela significativa da população brasileira encontre-se às voltas com um passado recente de plena destituição material e simbólica e um futuro que, embora alentado pela melhoria nas condições econômico-salariais, não a projeta solidamente como sujeito político internalizado, capaz de arrogar para si o papel de contribuir com as funções de autogoverno e representação de que tanto depende uma república democrática para reproduzir-se e atualizar-se ao longo do tempo. Isso quer dizer que, no limite, a ausência das precondições sociais, morais e culturais acima aludidas cria entraves à substantivação dessa nova classe enquanto componente fundamental do patrimônio democrático do país, uma vez que parte de sua condição estrutural de exclusão, qual seja, aquela relativa à inexistência de um repertório simbólico indutor de uma vida gregária, associativa e autodeterminada, permanece praticamente inalterada. Todavia, isso não quer dizer que inexistam formas através das quais os setores subalternos da sociedade brasileira se organizem e se reinventem mediante o quadro de mudança social e econômica através do qual se inserem nos viços e, sobretudo, nas intempéries do capitalismo contemporâneo. $\mathrm{O}$ problema reside no fato de que os valores e o ímpeto organizativo desses setores estão subordinados ao protagonismo ideológico desse novo capitalismo, o qual interpela os indivíduos a se desligarem de concepções holísticas e estruturais de sociedade para compreenderem-se como mônadas cujo sucesso ou fracasso resultam do nível de desenvolvimento de qualidades e atributos intrinsecamente pessoais, aplicáveis a projetos/empreendimentos quase sempre circunscritos a curtos intervalos de tempo, seguindo os ditames impostos pelo comportamento volátil dos mercados. Evocando Luc Boltanski e Eve Chiapello, mais especificamente a partir da obra intitulada $O$ novo espírito do capitalismo, Roberto Torres explica que esse capitalismo de novo tipo compele os indivíduos a agirem sob a égide do chamado "regime de projetos", que, nas palavras do autor,

a qual, somada à manutenção da estabilidade, corresponde nada mais nada menos que à realização de um completo programa de classe. Não o da classe trabalhadora organizada, cujo movimento iniciado no final da década de 1970 tinha por bandeira'a ruptura com o atual modelo econômico', mas à fração de classe que Paul Singer chamou de'subproletariado'ao analisar a estrutura social do Brasil no início dos anos 1980" (Singer, 2009, p. 98). Continuando a linha de raciocínio, Singer pontifica que "o subproletariado, a menos que organizado por movimentos como o MST, tende a ser politicamente constituído desde cima, como descobriu Marx a respeito dos camponeses da França em 1848. Atomizados pela sua inserção no sistema produtivo, necessitam de alguém que possa, desde o alto, receber a projeção de suas aspirações" (Singer, 2009, p. 99). 
(...) substitui as relações estáveis de cooperação e interdependência por "redes" em que a mobilidade e o desprendimento são percebidos em termos absolutos. Neste regime os "testes legítimos" passam a exigir entrega emocional e fidelidade a empreitadas de curto prazo, e em relações efêmeras que não permitem a avaliação e o reconhecimento de atributos que definem o status de uma profissão numa perspectiva de longo prazo. Sem esta perspectiva, os indivíduos são motivados a desenvolver disposições descartáveis, empregáveis na circunstância de cada projeto de curto prazo e incapazes de pautar relações de reconhecimento e interdependência generalizáveis de um contexto para outro (Torres, 2007, p. 93).

A religião torna-se, doravante, uma das formas precípuas através das quais essa ideologia é incorporada, pelas classes subalternas, sob o formato de organização. No caso em tela, o movimento religioso que entroniza os pressupostos individualistas supracitados chama-se pentecostalismo, sobretudo em sua vertente conhecida como neopentecostal ${ }^{6}$, portadora da chamada Teologia da Prosperidade (Freston, 1993; Mariano, 2005). Fundada num gnosticismo dualista, essa teologia baseia-se na premissa de que a emulação ritual travada pela fé contra as forças espirituais do mal é responsável pela viabilização de vitórias pessoais intramundanas, tais como alívio às aflições do corpo e da mente, sucesso profissional e financeiro, prestígio e ascensão social etc., tudo isso sintetizado pela operação de expulsão do demônio de suas vidas. Nas palavras de Ricardo Mariano,

Esta teologia está operando e promovendo forte inversão de valores no sistema axiológico pentecostal. Faz isso ao enfatizar quase que exclusivamente o retorno da fé nesta vida, pouco versando acerca da mais grandiosa promessa das religiões de salvação: a redenção após a morte. Além de que, em vez de valorizar temas bíblicos tradicionais de martírio, auto-sacrifício, isto é, a "mensagem da cruz" - que apregoa o ascetismo (...) e a perseverança dos justos no caminho estreito da salvação, apesar do sofrimento, das injustiças e perseguições promovidas pelos ímpios contra os servos de Deus -, a Teologia da Prosperidade valoriza a fé em Deus como meio de obter saúde, riqueza, felicidade, sucesso e poder terrenos (Mariano, 2005, p. 158, grifo no original).

${ }^{6}$ Dentre as principais denominações religiosas que pertencem a essa vertente neopentecostal estão as igrejas Universal do Reino de Deus, Internacional da Graça de Deus, Renascer em Cristo, Sara Nossa Terra e Mundial do Poder de Deus (fundadas, respectivamente, em 1977, 1980, 1986, 1992 e 1998). 
Merece destaque também a dimensão relevante atribuída ao dízimo e às ofertas ${ }^{7}$ como lastro para a consecução dos desígnios da fé na batalha espiritual; ou seja, quanto maior a contribuição pecuniária do dizimista, maiores são sua expressão de coragem e certeza da fé no poder de Deus, assim como maiores são as contrapartidas benéficas dessa fé traduzidas em bênçãos e milagres de Deus na vida material do fiel subserviente.

A internalização de valores privatistas na doutrina religiosa neopentecostal é propalada aos fiéis pela recursiva insistência no sucesso intramundano mediante a emulação espiritual, e pode ser considerada como um efeito de tomada de consciência dessa vertente religiosa quanto à gradual configuração de um indivíduo moderno que brota da periferia, privado muitas vezes de condições básicas de cidadania e, portanto, submetido a condições econômicas e sociais de profunda instabilidade, insegurança e abandono estatal, e que encontra na possibilidade de autorrealização e no empreendimento de si um mecanismo alternativo de ascensão social, prestígio e acesso à sociedade de consumo.

São de grande valia, nesse bojo, as constatações de Diana Nogueira de Oliveira Lima (2008), obtidas a partir de estudo etnográfico realizado com fiéis da IURD, pois permitem aferir com bastante acuidade de que maneira se processa, ao nível dos fiéis, a assimilação do enfático discurso sobre a prosperidade veiculado pela Igreja Universal.

Segundo Diana Nogueira, os fiéis por ela entrevistados não ocupam posição estratégica em nenhuma organização produtiva ou financeira, são pobres e muito precariamente escolarizados, não têm nenhuma qualificação

O dízimo jamais supera a proporção de $10 \%$ dos ganhos auferidos pelo fiel. No entanto, os neopentecostais diferem dos demais evangélicos em relação às ofertas, que variam em tamanho e frequência. A título de ilustração, a pesquisa Novo Nascimento, realizada pelo ISER em 1994, perguntou a fiéis de diversas denominações religiosas sobre a contribuição financeira que fizeram para suas respectivas igrejas, chegando à seguinte conclusão:"(...) embora tivessem rendas praticamente idênticas, os adeptos da [lgreja] Universal contribuíam mais e em maior número do que os da Assembléia de Deus: 27\% dos fiéis da Universal fizeram doações que ultrapassaram o valor do dízimo contra apenas $14 \%$ dos assembleianos; $17 \%$ dos seguidores do bispo Edir Macedo doaram quantias menores que o dízimo contra 25\% da Assembleia; 24\% (um quarto) dos primeiros não deram contribuição alguma contra 33\% (um terço) dos últimos; houve empate apenas entre os que contribuíram valor equivalente ao dízimo: $24 \%$ e $23 \%$, respectivamente. Dentre as igrejas evangélicas pesquisadas, os fiéis da Universal foram os que mais contribuíram com valores acima do dízimo, os que menos fizeram doações inferiores ao dízimo e, apesar da baixíssima renda da maioria deles, os que menos deixaram de contribuir. Merece destaque o fato de que dos crentes cuja renda não ultrapassava dois salários mínimos os da Universal foram os que mais doaram quantias superiores ao dízimo: $35 \%$ contra 20\% da média dos evangélicos" (Fernandes apud Mariano, 2005, p. 165) 
e, portanto, não se encontram em nenhuma categoria ocupacional, nunca tiveram experiência associativa tampouco foram beneficiados por nenhum mecanismo social de inserção. Basicamente, o que todos têm em comum resume-se apenas à força de trabalho, que poderia ser empenhada em algum emprego no setor da indústria. Todavia, como vivem em um contexto metropolitano de progressiva dificuldade de emprego e de baixos salários, enfrentam uma situação de marginalidade em relação ao sistema produtivo. Além disso, nas histórias de vida desses fiéis, o trabalho ou a inserção em um contexto de labor não eram uma referência para a constituição de sua identidade, e, no caso em tela, como eram jovens fiéis, encontravam-se na famigerada classificação de "adolescentes em conflito com a lei", antes de serem evangelizados.

Em geral, esses fiéis eram empreendedores de si mesmos antes ainda de aderirem à igreja. Ou trabalhavam por conta própria prestando pequenos serviços, ou ainda valiam-se do crime - e de estratégias para driblar a polícia - para auferirem seus recursos financeiros e nutriam verdadeiro desprezo por trabalhos repetitivos e extenuantes, normalmente atrelados a vínculos empregatícios. Em suma, a pesquisadora os descreveu como essencialmente autônomos, ou ainda, negativamente autônomos (Lima, 2008, p. 26), em função de suas condições de abandono e esquecimento pelas políticas sociais. Contudo,

embora isolados e fragilizados por conta desse isolamento no mercado de trabalho, adjetivá-los de "abandonados", “esquecidos", "excluídos" ou, enfim, "vítimas", seria, mais do que um equívoco interpretativo sobre o modo desses homens de camadas populares estarem em um mundo ausente de instituições inclusivas, um desrespeito à representação que fazem de si mesmos e que os moveu à conversão a essa denominação pentecostal que os ensina a trabalhar "com Deus" por uma "vida melhor" (Lima, 2008, p. 27).

A cosmologia da Igreja Universal concebe o fiel como um sócio de Deus, mediante a contrapartida do dízimo, atestando que este é a ferramenta precípua para que o fiel contribua para a "Obra de Deus", para que o "Mal" seja eliminado e para que a abundância possa chegar a todos. Segundo Ricardo Mariano, para o fiel receber a bênção da abundância, ele deve

(...) possuir uma fé inabalável, confessar a posse da benção, observar as leis da prosperidade, ou o que Mauss (1974), no "ensaio sobre a dádiva", nomeia de "princípio da reciprocidade", popularmente conhecido no Brasil pela expressão "é dando que 
se recebe". [Contudo], confessar nada tem a ver com pedir ou suplicar a Deus. Estas são atitudes reprováveis, demonstrações de pouca fé, sinais de ignorância do modo correto de como se relacionar com Deus. Os cristãos, em vez de implorar, devem decretar, determinar, exigir, reivindicar, em nome de Jesus, como Deus prescrevera, para "tomar posse das bênçãos" a que têm "direito" (Mariano, 2005, p. 154).

Para Diana Nogueira, o fiel troca o dízimo por coragem, para levar a cabo seus auspiciosos projetos empreendedores que visam a uma vida melhor (Lima, 2008, p. 28).

Além de socializados ritualisticamente como consortes nas carências, problemas e anseios vicejados, os fiéis neopentecostais são internalizados em uma esfera pública religiosa que possui uma estrutura administrativa centralizada, autoritária e organizada numa hierarquia eclesial formada por obreiros, pastores e bispos. Igualmente, é possível afirmar que tais instâncias religiosas têm fortes lideranças e se nutrem da oposição aos cultos afro-brasileiros; do mesmo modo, estimulam a expressividade emocional, colocam ênfase em rituais de cura e exorcismo, na guerra espiritual e na prosperidade. Nesse sentido, são bastante liberais no tocante a estereótipos de usos e costumes, têm uma estruturação empresarial significativa e adotam técnicas de marketing e gerenciamento modernos, sobretudo através do uso ostensivo dos meios de comunicação de massa e de técnicas de persuasão agressivas, o que as torna bastante modernas e adaptadas à realidade que as envolve (Siqueira, 2006; Campos, 2006).

Em linhas gerais, é possível dizer que, ao longo das últimas décadas, foi se constituindo, no Brasil, uma identidade cultural entre os menos favorecidos cuja interface com a dimensão secular se opera num registro moral, eminentemente religioso, mas orientado pragmaticamente para o êxito individual no mundo econômico. Tal identidade sustenta-se em afinidades eletivas entre o comportamento ávido e apetitivo de uma classe social emergente e uma disposição moral conservadora e não dialógica, por vezes polêmica, que exaspera publicamente rótulos pejorativos relacionados a alteridades sociais e contextos adversos e/ou desconhecidos, vistos em conjunto como ameaças à integridade ética da sociedade e de suas instituições centrais, entre as quais o mercado e a política. Dentro desse cadinho social, obviamente, são exíguos os espaços disponíveis para a constituição de um caldo de cultura capaz de produzir e sustentar consensos sociais mais amplos e legítimos acerca dos 
valores e princípios que devem regular a existência de uma sociedade tão complexa e plural como a brasileira; como consequência, cria-se uma tensão aguda entre os imperativos religiosos e o avanço da cidadania, sobretudo no que diz respeito à afirmação da laicidade nos princípios de justiça e, consequentemente, à construção de uma sociedade bem-ordenada ${ }^{8}$.

Ao invés de uma cultura cívica pluralista, baseada na comunicação e na persuasão, que permite mudanças, mas as modera por meio de um acordo político razoável entre contendores (Almond e Verba, 1963, p. 6), desponta, através do neopentecostalismo, uma modalidade potencialmente chauvinista de engajamento religioso na esfera pública, na qual liderados são submetidos aos cânones dogmáticos de seus líderes, que, por sua vez, instituem uma visão política sectária, contaminada por apriorismos morais, e uma visão arrivista de mercado, complementar à ideologia individualista e atomizante do capitalismo contemporâneo. Nas palavras de Rubem Barboza Filho, inspirado por John Rawls, o pentecostalismo, incluída a vertente neopentecostal,

(...) pouco tem a ver com a constituição de uma sociedade capaz de compartilhar, na sua pluralidade, uma ética transformadora. É eficaz para o que pretende, mas o que pretende não parece eficaz para um possível overlaping consensus em torno de uma democracia viva (Barboza Filho, 2011, p. 13).

Diante da articulação entre o quadro mais amplo de crise da política com a situação específica tratada neste artigo, urge atentar para a advertência feita por Chantal Mouffe a respeito da maneira como, em sua visão, se expressa o fenômeno político contemporâneo. Segundo ela,

o que está acontecendo na atualidade não é a desaparição do político em sua dimensão conflitual, mas algo diferente. $\mathrm{O}$ que ocorre é que atualmente o político se expressa

\footnotetext{
Segundo John Rawls, "para formular uma noção realista de sociedade bem-ordenada, dadas as condições históricas do mundo moderno, não dizemos que sua concepção política pública de justiça é afirmada pelos cidadãos a partir de uma mesma doutrina abrangente. O fato do pluralismo razoável implica que não existe doutrina, total ou parcialmente abrangente, com a qual todos os cidadãos ou possam concordar para decidir as questões fundamentais de justiça política. Pelo contrário, dizemos que numa sociedade bem-ordenada, a concepção política é afirmada por aquilo que denominações um consenso sobreposto razoável. Entendemos por isso que a concepção política está alicerçada em doutrinas religiosas, filosóficas e morais razoáveis embora opostas, que ganham um corpo significativo de adeptos e perduram ao longo do tempo de uma geração para outra. Esta é, creio eu, a base mais razoável de unidade política e social disponível para os cidadãos de uma sociedade democrática" (Rawls, 2003, p. 45).
} 
num registro moral. Em outras palavras, ainda consiste numa relação de diferença do tipo nós/eles, mas esta relação, ao invés de ser definida mediante categorias políticas, se estabelece agora em termos morais. No lugar de uma luta entre "esquerda e direita", nos enfrentamos em uma luta entre "bem e mal"' (Mouffe, 2009, p. 12).

\section{Esfera pública, neopentecostalismo e democracia no Brasil}

No Brasil, país marcado por processos de modernização com rasgos desenvolvimentistas carentes da dimensão republicana, a transição da ordem senhorial-escravocrata para a ordem social competitiva cumpriu o andamento das revoluções passivas (Vianna, 2004), implicando um processo progressivo de realização do moderno em que, por meio da diferenciação societal - basicamente, pela aparição e afirmação de novos papéis sociais de desempenho incompatível com a ordem tradicional -, o sistema de orientação racional da ação se instalou em coexistência com a ordem patrimonial, criando para as classes dominantes (sobretudo as elites oligárquicas e a burguesia industrial ascendente) a possibilidade de extrair vantagem tanto do moderno como do atraso. Para essas classes, portanto, foi vantajoso tirar proveito dos tempos desiguais e da heterogeneidade da sociedade brasileira, mobilizando as vantagens que decorriam tanto do atraso quanto do adiantamento das populações.

Nesse sentido, como avalia Luiz Werneck Vianna,

(...) se o Estado nacional nasce "bastante moderno", apto à "modernização ulterior de suas funções econômicas, sociais e culturais", matriz efetiva da expansão do liberalismo no país, desde a sua origem mantém a marca de uma convivência com uma ordem antitética à sua, que, longe de ser impeditiva de sua afirmação, a torna possível, sobretudo por consistir na base econômica a partir da qual ela vai poder operar a sua forma de inscrição no capitalismo mundial (Vianna, 1999a, p. 40).

Para uma nação que se fez moderna, capitalista, à luz da preservação, por muitas décadas, do controle político e social oligárquico, como se dá, hodiernamente, o equacionamento da questão social, mediante o quadro de

No original: "(...) lo que está aconteciendo en la actualidad no es la desaparición de lo político en su dimensión adversarial, sino algo diferente. Lo que ocurre es que actualmente lo político se expressa en un registro moral. En otras palavras, aún consiste en un discriminación nosotros/ellos, pero el nosotros/ ellos, en lugar de ser definido mediante categorías políticas, se establece ahora en términos morales. En lugar de una lucha entre 'izquierda y derecha' nos enfrentamos a una lucha entre 'bien y mal'". 
inserção institucional da democracia em uma sociedade densamente urbana, industrial, inserida no contexto de mercado e atravessada por pressões desestabilizadoras do capitalismo financeiro internacional? Sem dúvida, a questão social ora sobressalente reside na dificuldade insistente - porque faltaram as mediações político-históricas de maturação da influência das classes subalternas na organização do capitalismo nacional - em expandir os direitos de cidadania.

(...) Num contexto em que gradualmente consolida-se um sistema político democrático, deixa de ocorrer um enraizamento organizatório e reivindicativo que consolide um conjunto de direitos básicos. Eles podem estar na Carta de 1988, mas não se traduzem no fortalecimento de um campo institucional de negociação de interesses e na arbitragem de conflitos, nem em políticas sociais de alcance massivo: não ocorreram processos que levassem à consolidação de uma condição do empowerment de grupos e categorias da sociedade civil (Kowarick, 2009, p. 77).

Jamais houve, no Brasil, instituições políticas sindicais ou comunitárias com força suficiente para garantir a efetivação de direitos básicos do mundo do trabalho ou proteger e retirar os subalternos das intempéries do mundo urbano.

Houve, sem dúvida, ilhas de modernização econômica e dinamização social, cujo exemplo mais evidente foi o município paulista de São Bernardo do Campo dos anos 1970 e 1980, energizado pelos trabalhadores das grandes empresas, pela ação reivindicatória impulsionada pelo "novo sindicalismo", pelo emaranhado de bairros operário-populares, onde pipocavam múltiplas lutas urbanas, nas quais as Comunidades Eclesiais de Base (CEBs) tinham presença significativa e, neste contexto de ebulição social e política, nasce o Partido dos Trabalhadores, ao mesmo tempo impulsionado e impulsionador dos movimentos sociais (Kowarick, 2009, p. 78) .

No entanto, essa foi uma experiência limitada no tempo e no espaço, espécie de luz que iluminou as ações políticas nos seus esforços de ampliar os direitos que permaneciam restritos a um pálido e atrofiado Estado de Bem-Estar. Atualmente, o "ornitorrinco" social existente - expressão cunhada por Francisco de Oliveira (2003) para designar os efeitos colaterais concatenados com a lógica da modernização periférica - se abate de maneira 
gutural sobre uma extensa sociedade civil desorganizada (sobretudo em seus setores subalternos), que encontra à sua frente um verdadeiro compêndio de insalubridades da vida urbana, contra o qual se debate, nos casos mais desesperados, uma parcela feroz dos pobres que se transformaram em bandidos e traficantes, e que representam a expressão-limite de uma sociedade esgarçada, forçada a correr atrás do êxito a qualquer preço, liquidando qualquer valor civilizatório (Lahuerta, 2001).

Esse conjunto social que se encontra em condições de vulnerabilidade social, mas que deseja se integrar, material e moralmente, à vida social em sua lógica hegemônica - privatista, hedonista e competitiva -, materializa a figura do indivíduo como matriz do interesse no registro da modernidade periférica brasileira. É justamente a partir da agregação de parte desses indivíduos numa cosmovisão racionalizadora do mundo social, em linguagem religiosa e palatável para "educar seu interesse", que o neopentecostalismo ganha relevância para se compreender a dinâmica de constituição do sujeito político da modernidade tardia (e periférica), pois ele faz com que os que tradicionalmente se encontram fora do sistema político se sintam abrigados no interior de uma comunidade moral que pratica uma espécie de subpolítica da afirmação social, mantendo, paradoxalmente, sua clientela religiosa alijada do circuito democrático do poder e da socialização política pautada na educação para a cidadania e para o reconhecimento do caráter universal dos direitos - o que lhe é bastante funcional, pois é justamente na combinação dos modelos patrimonialista ${ }^{10}$ e burocrático-organizacional que o referido movimento religioso consegue administrar o insólito capital religioso que construiu, retraduzindo-o no interior da organização religiosa sob a forma de recursos políticos e financeiros a serem autarquicamente geridos pelos altos funcionários da organização. Síntese infame e expressão imatura de organização política da sociedade civil, o neopentecostalismo conforma um novo processo de acomodação do atraso e do moderno na constituição do fenômeno político no Brasil contemporâneo.

10 Com clara inspiração no catolicismo ultramontano, posto que rigidamente controlado por um governo eclesiástico episcopal, centralizado na figura do bispo Edir Macedo, com nítidas demarcações de controle administrativo e poder político e avesso a influências externas, inclusive da própria comunidade religiosa. 


\section{Neopentecostalismo, novo desenvolvimentismo e cultura política no Brasil contemporâneo}

Dados censitários divulgados recentemente pelo IBGE têm ratificado prognósticos que acenam para a continuidade da curva de declínio de católicos vis-à-vis o aumento do número de evangélicos no país. De acordo com os dados, os pentecostais são os maiores responsáveis pelo crescimento demográfico desse grupo religioso, tendo passado de 17.617.307 adeptos em 2000 para 25.370.484 em 2010, perfazendo um expressivo crescimento de $44 \%$ em dez anos. Em contrapartida, os evangélicos de missão passaram de 6.939.765 de adeptos em 2000 para 7.686.827 em 2010, perfazendo um crescimento de apenas $11 \%$ no mesmo intervalo de tempo. Juntos, entretanto, os evangélicos (de missão e pentecostal) somam hoje um total de $22,2 \%$ da população brasileira. Se observarmos uma ampla série histórica, que cobre o período de 1940 a 2000, verificar-se-á que o crescimento desse grupo religioso, puxado sobremaneira pelo componente pentecostal, é especialmente significativo a partir da década de 1990, conforme aponta a tabela 1 , a seguir.

Tabela 1. Religiões do Brasil de 1940 a 2000, em porcentagem

\begin{tabular}{c|c|c|c|c|c|c|c}
\hline religião & 1940 & 1950 & 1960 & 1970 & 1980 & 1990 & 2000 \\
\hline católicos & 95,2 & 93,7 & 93,1 & 91,1 & 89,2 & 83,3 & 73,8 \\
\hline evangélicos & 2,6 & 3,4 & 4,0 & 5,8 & 6,6 & 9,0 & 15,4 \\
\hline outras religiões & 1,9 & 2,4 & 2,4 & 2,3 & 2,5 & 2,9 & 3,5 \\
\hline sem religião & 0,2 & 0,5 & 0,5 & 0,8 & 1,6 & 4,8 & 7,3 \\
\hline total $^{*}$ & 100 & 100 & 100 & 100 & 100 & 100 & 100 \\
\hline
\end{tabular}

Fonte: IBGE, Censos demográficos.

* Não inclui religião não declarada e não determinada.

Entretanto, é imperioso ir além das estatísticas para se entender o sentido profundo dessa transformação em curso, sobretudo quando verificadas as relações causais existentes entre o crescimento desse vértice religioso e as demais esferas da vida social brasileira.

Em primeiro lugar, é preciso esclarecer que o que se costuma chamar, de forma ampla e genérica, de movimento pentecostal, resulta de um ter- 
reno religioso bastante fragmentário em termos denominacionais ${ }^{11}$, além de altamente suscetível, em curtos espaços de tempo, a inflexões em suas respectivas igrejas, gnosiologias e liturgias, tornando difícil o enraizamento de um sistema axiológico mais amplo e sistemático ${ }^{12}$.

Em segundo lugar, e para além da esfera teológica e organizacional, o pentecostalismo, sobretudo a vertente neopentecostal, é um movimento religioso e cultural adstrito à recente modernização da periferia do sistema capitalista mundial, uma vez que seu timbre cultural é uma função direta da intersecção de dois processos sociais coetâneos, quais sejam: o de mudança social orientada pela expansão da sociedade de consumo (sobretudo a partir da aceleração do crescimento econômico durante o regime militar) e o de insuficiência (ou ainda, debilidade) das capacidades institucionais do Estado, por um lado, e organizativas da sociedade civil, por outro, no tocante ao enfrentamento dos problemas de marginalização social ocasionados pela excessiva desigualdade econômica e pelo déficit de capitais simbólicos (instrução escolar, renda, experiência de participação em organizações sindical e política etc.) necessários ao fortalecimento de uma cultura política cívica e democrática.

No que tange especificamente ao problema do déficit de capitais simbólicos supracitado, basta observar que, a partir da década 1990, todo um conjunto de conflitos habitualmente ligados à esfera da política passou a ser adjudicado ao arbítrio do Poder Judiciário, mormente do Supremo Tribunal Federal, a quem passou a caber, por intermédio do instituto do controle judicial de constitucionalidade, a responsabilidade pela resolução de parte significativa das contendas originárias do próprio Estado e da sociedade civil organizada (Vianna, 1999b). Trata-se de um sintoma de que, do ponto de vista substantivo da experiência democrática, nossa sociedade civil - mesmo a sua parcela mais empoderada - vive um momento dramático de ausência de autogoverno e, ato contínuo, de baixo repertório político e ideológico que lhe permita a apropriação de espaços institucionalizados de conflito e de concerto dialógico isentos da mediação de instituições relativamente autárquicas e autorreferidas, como é o caso do Judiciário.

\footnotetext{
11 Paul Freston (1993) realizou uma das mais criteriosas classificações a respeito das transformações históricas do campo religioso pentecostal no Brasil.

12 Em contrapartida, por exemplo, o catolicismo mostra capacidade de manutenção diacrônica de um mínimo de coesão hierárquica e organicidade teológica no interior de (e entre) as distintas ordens e estruturas episcopais e eclesiásticas a ele subordinadas
} 
Além disso, voltando à dimensão do crescimento da sociedade de consumo, vivemos, atualmente, sob a égide da retomada de uma economia política desenvolvimentista que, entre suas expoentes realizações, universalizou a linguagem instrumental e apetitiva do mercado no tecido das relações sociais, garantindo renda, crédito e acesso a bens de consumo caros - e idiossincraticamente ostentatórios - a praticamente todos os segmentos socioeconômicos da sociedade brasileira.

O baixo repertório simbólico indutor de uma vida gregária e (efetivamente) autodeterminada, aliado aos efeitos tóxicos do hedonismo derivado do consumo conspícuo, nos oferece um mapa da socialização política e cultural do capitalismo periférico brasileiro, a quem a modernização consagrou, de forma sui generis, os primados do individualismo e da liberdade, conformando uma esfera pública caracterizada por um ambiente institucionalmente democrático, porém pouco permeado por uma cultura política capaz de promover a socialização dos valores da participação, da justiça e da equidade.

Nesse cenário típico da modernidade periférica brasileira, as ações sociais orientadas ao êxito pautam-se pela acumulação de "experiências de sucesso" situadas à margem e aquém dos liames que orbitam o mundo do trabalho e da produção industrial, flertando, não raras vezes, com o improviso, a aleivosia, o "jeitinho" e, o que é pior, com a violência e a criminalidade organizada - todos esses exemplos de conduta que passaram a se constituir, pela sua reiteração e seu reforçamento, em um ethos imanente e organizador da vida social em suas diversas esferas - inclusive a religiosa (Lahuerta, 2001).

O Brasil, portanto, possui uma sociedade em que as oportunidades democráticas dadas à agência individual convertem-se em transgressão à norma cogente, sem que isso represente, no seu conjunto de práticas hegemônicas, algum dado de contestação contracultural e de afirmação de uma cidadania mais justa e inclusiva.

O neopentecostalismo, com todos os seus matizes, representa a vocalização de um ethos popular cultivado silenciosamente durante décadas de desamparo político e legal por parte do conjunto mais amplo da sociedade brasileira. Nesse sentido, tal movimento religioso pode ser lido como expressão da modernização conservadora do país - baseada na organização autoritária do desenvolvimento capitalista -, uma vez que os valores que ele organiza subordinam-se à concretização do ideal, pouco republicano, de mobilidade social nos termos estritos da lógica predatória do mercado. 
Ademais, como se verifica na Teologia da Prosperidade, a internalização de um ethos religioso fundado na emulação pecuniária e na absolutização ética do egocentrismo reflete a hodierna constituição de uma base ideológica mais ampla da sociedade brasileira contemporânea, que institui e entroniza um indivíduo valorativamente precário, que emerge dos interstícios da vida social para o cerne do capitalismo pós-industrial "queimando as etapas" do modelo clássico de modernização, fulcrado na organização política dos interesses e valores do mundo do trabalho pari passu com o desenvolvimento do modo de produção capitalista e da superestrutura que o envolve.

A ascese religiosa intramundana incorporada pelo indivíduo da modernidade periférica é, em parte, condizente com a premissa neoliberal de libertação dos indivíduos de qualquer convicção moral e ideológica "quente" e totalizante, uma vez que flexibiliza sanções comportamentais tornando-as ajustáveis e cambiantes, seguindo, assim, as conveniências e veleidades dos costumes orientados pela sociedade de consumo. No entanto, há nessa suposta libertação um resíduo hermético de certezas sobrenaturais e convicções morais que preservam (ou restauram) a confiança desse indivíduo na existência de uma "boa sociedade", ou, noutros termos, de um conjunto mínimo de valores sem os quais o funcionamento do mundo social entraria invariavelmente em colapso. Trata-se, em larga medida, da transformação desse tipo de moralidade em um recurso político muito poderoso, porque revitaliza o sentido de existência comunitária que dá a muitos uma identidade e um repertório comum de ação para lidar com as ambivalências e modificações da vida contemporânea.

Essa capacidade de injunção normativa emanada da autoridade moral religiosa vem recolocando, do ponto de vista político-normativo, um perigoso engodo. Isso porque, numa democracia em que as liberdades são protegidas de maneira integral, a sociedade se manifesta em toda a sua complexidade, irrigando o campo político com novas demandas (bioéticas, étnico-raciais, de gênero, entre outras) que lutam pela ampliação do campo dos direitos, pelo reconhecimento de sua existência moral e, consequentemente, pela redefinição dos critérios de justiça. Quando a democracia permite a pluralidade de vozes e lutas, mais interesses distintos são representados e mais difusos são os lugares de construção da vontade política, de modo que novos desafios surgem naturalmente a respeito da forma como essas questões serão negociadas para que o consenso seja fruto de uma deliberação amplamente legítima. 
Entretanto, como vimos presenciando recentemente, sobretudo nas últimas eleições presidenciais brasileiras (Stycer, 2010), há um nítido aumento do clamor popular para que lideranças políticas nacionais assumam explicitamente compromissos de cunho moral, dentre os quais aqueles relacionados com as proibições do aborto, da união homoafetiva e da descriminalização das drogas. A assunção de compromissos como esses em arenas de competição plebiscitária fere a ética do pluralismo democrático, que visa proteger o direito que têm minorias político-sociais de não serem submetidas a posturas e decisões tomadas em caráter plebiscitário, durante as eleições.

À guisa de conclusão, a contaminação das esferas do mercado e da política pela práxis religiosa contemporânea, como demonstrado sumariamente neste texto, tem sua explicação e razão de ser gravadas na história da modernização conservadora do país, cujos contornos autoritários declinam-se cabalmente sobre a atual carência de um habitus político normativamente orientado por uma trajetória de construção efetiva da cidadania e dos direitos (Lahuerta, 2003). Entendemos, portanto, que as "misérias" da democracia no país estão diretamente relacionadas com a longa marcha dessa modernização secular $\grave{a}$ brasileira, que obliterou, ou melhor, impediu, a socialização ativa das classes subalternas nos espólios do progresso material e institucional alcançados na luta contra o subdesenvolvimento, cujas consequências para nossa cultura política e cidadania são de uma dramaticidade irretorquível ${ }^{13}$, tendo em vista, sobretudo, o sentido profundo dos dados censitários supracitados, que apontam a consolidação de uma religiosidade profundamente intramundana, porém detentora de uma proposta salvacionista e mistificadora, arrivista e pouco cevada nos valores de uma república democrática.

\section{Conclusão}

A partir da imagem da coruja de Minerva, que só alça voo ao entardecer, o filósofo alemão Hegel postulou a imanência da História na conformação dos

\footnotetext{
Urge pontuar que, ao relacionar a atuação dos evangélicos com a cultura política brasileira, deve-se considerar a assimilação, por parte das lideranças religiosas implicadas, da lógica político-partidária brasileira e da absorção seletiva de temas das agendas dos movimentos sociais em curso na sociedade (Machado, 2006, p. 46). Ademais, como bem demonstra Maria das Dores Campos Machado, não se pode ignorar que fatores objetivos, "(...) como a ampliação da pobreza, o descaso com a educação e a saúde da população e mesmo as características de nossas instituições políticas favorecem a difusão de práticas clientelísticas e corporativas entre os sujeitos políticos contemporâneos, e que tais fatores precisam ser enfrentados seriamente se o nosso objetivo for o fortalecimento da democracia" (Machado, 2006, p. 46-47).
} 
fenômenos sociais, os quais só podem vir a ser inteligíveis e, por conseguinte, passíveis de interpretação, ex post facto. Para a teoria social contemporânea, esse axioma hegeliano tornou-se ponto de partida para a construção de uma ontologia social a partir do eixo que os processos históricos concretos conferem às transformações e mudanças desencadeadas pelas pressões inexoráveis impostas pela modernização capitalista em âmbito global.

Nesse sentido, o fenômeno político no mundo contemporâneo corresponde à revelação singular da experiência humana no atual estágio da modernidade, como o culminar de um processo histórico que consagrou a primazia do indivíduo - matizado em diversas formas expressivas e distintas possibilidades de ação, reprodução e transformação - na demarcação dos rumos das estruturas político-institucionais que medeiam as relações entre a sociedade, o Estado e as forças tecnológicas e econômico-materiais.

Nesse complexo constituído pela intrincada relação entre dois entes ou estruturas distintas $^{14}$ - a sociedade e seus segmentos de classe, com seus respectivos subgrupos, subjetividades, valores, crenças etc., e o universo sistêmico constituído, grosso modo, pelas estruturas técnico-científicas e informacionais, pelo mercado e o Estado -, o indivíduo emerge como sujeito, a um só tempo agente e paciente, que é livre para eleger um caminho pessoal a seguir, mas que é sobredeterminado por circunstâncias posicionais (classe social e status de classe), sistêmicas (as instituições em largo espectro, a ciência e os processos econômico-materiais) e por limites e efeitos imponderáveis da transformação modernizadora (crises ecológica e financeira, fundamentalismo e integrismo moral-religioso, violência e deterioração endêmica das formas de socialização, ameaças naturais e de guerras apocalípticas etc.).

Buscando discutir a dimensão crítica das transformações desse fenômeno político contemporâneo no Brasil, em cujo seio permanece a mácula de uma modernização conservadora que prejudicou o desenvolvimento da democracia, intentou-se investigar o neopentecostalismo enquanto religião organicamente ligada a uma parcela social que, embora economicamente ascendente nos últimos anos, ainda está a internalizar a formação/consolidação de um liberalismo democrático recente na história republicana brasileira e coetâneo aos abalos estruturais infligidos pelas transformações políticas e culturais decorrentes das mudanças tecnológicas e do novo regime de acumulação capitalista.

14 São utilizados aqui os conceitos de "mundo da vida" e "sistema" desenvolvidos por Jürgen Habermas (1992). 
Dentro desse cenário, portanto, o neopentecostalismo mostra sua relevância, pois tem oferecido sentido pragmático/existencial a um conjunto populacional historicamente marginalizado e debilmente articulado com as instituições políticas democráticas, para quem o caminho para se evitarem os riscos e ambivalências dessa nova etapa da modernidade - que submete os indivíduos à convivência constante com o risco e a incerteza - é decorrente de uma matriz moral e religiosa que preenche os espaços vazios deixados pela baixa intervenção protetora do Estado e pela escassa experiência democrática e de organização política das classes subalternas.

Isso posto, o discurso e a práxis do neopentecostalismo são concebidos neste artigo como um matiz do crescente individualismo cultural do mundo contemporâneo, que se apoia peculiarmente na adaptação plena à semântica predominante do indivíduo privatista - sequioso de prosperidade, confiança, afeto, controle existencial etc., mas que não se deixa penetrar pelos problemas que não lhe dizem respeito e que, portanto, se recusa ao envolvimento com a coletividade.

Mobilizando a noção de modernidade periférica, este trabalho procurou subsumir a lógica da modernização capitalista recente aos elementos deletérios dessa transformação nas esferas política e cultural do Brasil. Dentro desse cadinho, tornou-se possível analisar os componentes que permitiram a alavancagem da política em registro moral e religioso, em detrimento de categorias eminentemente políticas, dentro do Estado moderno e da esfera pública brasileiros.

Assim sendo, frente aos desafios que a modernização capitalista impõe às condições de estruturação da política na contemporaneidade, o neopentecostalismo vem demonstrando sua força e seu bem-sucedido processo de inserção na esfera pública brasileira, uma vez que expressa elementos típicos dessa modernidade periférica.

Tal movimento religioso tem ressignificado o ideal de indivíduo como único responsável por sua sorte, estabelecendo uma peculiar versão do self-made man a partir de liturgias que desafiam os fiéis a alcançarem prosperidade material por meio de sucessivas emulações espirituais e ofertas constantes e cada vez mais robustas de dízimo, sem sequer tangenciar a ética do trabalho como instrumento de mobilidade social de cunho individualista, tão presente no ascetismo religioso do protestantismo histórico.

Igualmente, o neopentecostalismo fala a um fiel mais passivo, que pertence a estratos da população com elevados déficits materiais e simbólicos 
(baixos níveis de renda e escolarização, além de pouco - ou nenhum - recurso ou experiência político-organizatória) e que, portanto, está disponível para ser resgatado pelo discurso salvacionista-religioso. Para arregimentar esses fiéis, os neopentecostais vêm construindo e aperfeiçoando o uso de sua estrutura organizacional moderna e empreendedora, capaz de articular de maneira eficiente sua máquina administrativa, política e eclesial.

Por conseguinte, como já afirmado na primeira parte do artigo, os fiéis neopentecostais são internalizados em uma esfera pública religiosa que possui uma estrutura administrativa centralizada, autoritária e organizada numa hierarquia eclesial formada por obreiros, pastores e bispos - com nítida inspiração no modelo corporativista ultramontano que influenciou os processos de modernização do Estado e de diversas outras instituições no país. Dentro dessa estrutura, os movimentos neopentecostais orientam verticalmente seus religiosos e fiéis, incutindo-lhes confiança no funcionamento das leis naturais do mercado e autoconfiança para operar os mecanismos subjacentes a essa lógica.

Outro aspecto relevante dos neopentecostais é a presença no campo midiático, sobretudo por possuírem trânsito permanente em canais abertos de radio e televisão, e, mais ainda, por possuírem, no caso específico da IURD, os controles financeiro, estratégico e institucional de uma das mais influentes redes de televisão do país. Ou seja, através da Rede Record, transferem sua weltanschauung para a trama dos interesses políticos e simbólico-culturais da vida cotidiana, expandindo, assim, sua força e capacidade de influência para uma tessitura social e institucional mais ampla, incluídos aí o mercado e o Estado.

Em resumo, os neopentecostais capturam, através de uma práxis religiosa que transcende os liames de um gnosticismo esotérico, elementos que os conectam com o processo de crise e transformação do fenômeno político contemporâneo: radicando sua presença no campo midiático e, num sentido mais amplo, numa cultura audiovisual cada vez mais intensa que conforma uma esfera pública emergente (cf. Sartori, 2000); fazendo o jogo da subpolítica na trama dos complexos infraestruturais que fugiram paulatinamente ao domínio superestrutural do Estado; internalizando a ética do "regime de projetos" em oposição à declinante ética do trabalho que controlava as energias de uma sociedade salarial atualmente em crise; e, o que é mais importante, fazendo tudo isso em sintonia com a lógica da modernização periférica brasileira - que combina atraso e moderno -, ao sustentar uma cultura organizacional e política 
autoritária que contribui para a deterioração de uma cidadania política bem compreendida que possa alargar o alcance e o campo dos direitos através da participação e do controle democráticos da sociedade sobre o Estado.

Percebe-se, a partir de todos os dados coligidos e operacionalizados neste trabalho, o que Wanderley Guilherme dos Santos (1992) chamou de híbrido institucional brasileiro, que se traduz numa modalidade de democracia peculiar em que a esfera poliárquica se sobrepõe a grandes vazios institucionais, nos quais o que prevalece é a ausência de direitos e a impossibilidade de acesso às estruturas da ordem legal, reduzindo-se drasticamente as condições de exercício da cidadania (Diniz, 2007, p. 40). O quadro resultante desse processo, qual seja, a retração extrema da esfera pública, desloca os indivíduos socialmente vulneráveis para o auge do privatismo, em que arranjos tradicionais travestidos de novos, no caso em tela a religião, infundem pactos sociais pautados pelo princípio da subsidiaridade, no qual prevalece a máxima de que a instância mais próxima do indivíduo necessitado é que deve procurar auxiliá-lo. No caso da Teologia da Prosperidade, um indivíduo narcísico e hedonista, para quem sua fé e Deus são as ferramentas necessárias - e suficientes - para a superação de todas as contradições, ambivalências e riscos da socialização no mundo contemporâneo.

\section{Referências}

ALMOND, Gabriel \& VERBA, Sidney (1963). The civic culture:political attitudes and democracy in five nations. Boston: Little, Brown and Company.

AVRITZER, Leonardo (2002). "Em busca de um padrão de cidadania mundial”. Lua Nova, n. 55-56, p. 29-55.

BABOZA FILHO, Rubem (2011). "Razão, religião e democracia”. Boletim CEDES, outubro/dezembro. Disponível em: http://www.cis.puc-rio.br/ cedes. Acessado em 30 mai. 2014.

BECK, Ulrich et al. (1995). Modernização reflexiva: política, tradição e estética na ordem social moderna. São Paulo: Editora Unesp.

BELLUZZO, Luiz Gonzaga (2013). "Os anos do povo”, em SADER, Emir (org.). Lula e Dilma: 10 anos de governos pós-neoliberais no Brasil. São Paulo: Boitempo.

CAMPOS, Leonildo Silveira (2006). "Cultura, liderança e recrutamento em organizações religiosas: o caso da Igreja Universal do Reino de Deus”. Organizações em Contexto, v. 2, n. 3, p. 102-138. 
DINIZ, Eli (2007). “O pós-consenso de Washington: globalização, Estado e governabilidade reexaminados”, em DINIZ, Eli (org.). Globalização, Estado e desenvolvimento: dilemas do Brasil no novo milênio. Rio de Janeiro: Editora FGV.

FRESTON, Paul (1993). Protestantes e política no Brasil: da Constituinte ao Impeachment. Tese (Doutorado em Ciências Sociais) - Instituto de Filosofia e Ciências Humanas, Unicamp, Campinas.

GIDDENS, Anthony (2002). Modernidade e identidade. Rio de Janeiro: Jorge Zahar.

HABERMAS, Jürgen (1992). Teoría de la acción comunicativa. Vol. II. Crítica de la razón funcionalista. Madrid: Taurus.

HARVEY, David (2007). Condição pós-moderna. São Paulo: Loyola.

KOWARICK, Lúcio (2009). Viver em risco: sobre a vulnerabilidade socioeconômica e civil. São Paulo: Editora 34.

LAHUERTA, Milton (1999). Intelectuais e transição: entre a política e profissão. Tese (Doutorado em Ciência Política) - Faculdade de Filosofia, Letras e Ciências Humanas, USP, São Paulo.

(2001). "Brasil, a democracia difícil: violência e irresponsabilidade cívica. Política Democrática, n. 1, p. 83-96.

(2003). "O século XX brasileiro: autoritarismo, modernização, democracia”, em AGGIO, Alberto \& LAHUERTA, Manuel (orgs.). Pensar o século XX: problemas políticos e história nacional na América Latina. São Paulo: Editora da Unesp.

LIMA, Diana Nogueira de Oliveira (2008). “Prosperidade’ na década de 1990: etnografia do compromisso de trabalho entre Deus e o fiel da Igreja Universal do Reino de Deus". Dados, v. 51, n. 1, p. 7-35.

MACHADO, Maria das Dores Campos (2006). Política e religião: a participação dos evangélicos nas eleições. Rio de Janeiro: Editora FGV.

MANIN, Bernard (1997). The principles of representative government. Cambridge: Cambridge University Press.

MARIANO, Ricardo (2005). Neopentecostais: sociologia do novo pentecostalismo no Brasil. São Paulo: Loyola.

MARSHALL, Thomas H. (1967). Cidadania, classe social e status. Rio de Janeiro: Zahar.

MOUFFE, Chantal (2009). En torno a lo político. Buenos Aires: Fondo de Cultura Económica. 
NERI, Marcelo (2010). A nova classe média: o lado brilhante dos pobres. Rio de Janeiro: Editora FGV.

OFFE, Claus (1984). “A democracia partidária competitiva e o 'welfare state’ keynesiano: fatores de estabilidade e desorganização", em Problemas estruturais do estado capitalista. Rio de Janeiro: Tempo Brasileiro.

OLIVEIRA, Francisco de (2003) Crítica à razão dualista / O ornitorrinco. São Paulo: Boitempo.

RAWLS, John (2003). Justiça como equidade. São Paulo: Martins Fontes.

SANTOS, Wanderley Guilherme (1992). "Fronteiras do Estado mínimo: indicações sobre o híbrido institucional brasileiro”, em VELLOSO, João Paulo dos Reis (org.). O Brasil e as reformas políticas. Rio de Janeiro: José Olympio.

(1993). Razões da desordem. Rio de Janeiro: Rocco.

(2005). "O conservadorismo obsoleto do status quo", em CAVALCANTI, Biano S.; RUEDIGER, Marco Aurélio \& SOBREIRA, Rogério (orgs.). Desenvolvimento e construção nacional: políticas públicas. Rio de Janeiro: Editora FGV.

SARTORI, Giovanni (2000). Homo Videns: televisão e pós-pensamento. Lisboa: Terramar.

SINGER, André (2009). "Raízes sociais e ideológicas do lulismo". Novos Estudos, n. 85, p. 83-102.

SIQUEIRA, Deis (2006). "Religiosidade contemporânea brasileira: estilo de vida e reflexividade". Sociedade e Cultura, v. 9, n. 1, p. 13-26.

SOUZA, Jesse (2012). Os batalhadores brasileiros: nova classe média ou nova classe trabalhadora? Belo Horizonte: Editora UFMG.

STYCER, Maurício (2010). "Brasil regride séculos com programa eleitoral sobre Deus, aborto e família”. Uol. Eleições 2010, 8 out. Disponível em: http://eleicoes.uol.com.br/2010/ultimas-noticias/2010/10/08/brasilregride-seculos-com-programa-eleitoral-sobre-deus-aborto-e-familia. jhtm. Acessado em 10 ago. 2013.

TORRES, Roberto (2007). "O neopentecostalismo e o novo espírito o capitalismo na modernidade periférica”. Perspectivas, n. 32, p. 85-125. URBINATI, Nadia (2006). Representative democracy: principles \& genealogy. Chicago: University of Chicago Press.

VIANNA, Luiz Werneck (1999a) "Weber e a interpretação do Brasil”, em Novos Estudos, n. 53, p. 33-47. 
(1999b) "A judicialização da política no Brasil”, em VIANNA, Luiz Werneck et al.. A judicialização da política e das relações sociais no brasil. Rio de Janeiro: Revan. (2004) A revolução passiva: iberismo e americanismo no Brasil. 2. ed. Rio de Janeiro: Revan.

\section{Resumo}

Este trabalho se propõe a demonstrar que o fenômeno pentecostal brasileiro, mormente o neopentecostalismo e sua "Teologia da Prosperidade", representa a vocalização de um ethos privatista cultivado silenciosamente durante décadas de desamparo político e legal por parte do conjunto mais amplo e vulnerável da sociedade brasileira. Neste artigo sustenta-se que o neopentecostalismo desponta como organizador de uma cultura política marcada pela intersecção de dois processos sociais coetâneos, quais sejam: o de mudança social orientada pela expansão da sociedade de consumo e o de insuficiência das capacidades institucionais do Estado, por um lado, e organizativas da sociedade civil, por outro, no tocante ao enfrentamento dos problemas de marginalização social ocasionados pela excessiva desigualdade econômica e pelo déficit de capitais simbólicos necessários ao fortalecimento de uma cultura política cívica e democrática.

Palavras-chave: neopentecostalismo; cultura política; democracia; modernidade periférica.

\section{Abstract}

This paper aims to demonstrate that the Brazilian Pentecostal phenomenon, especially neo-Pentecostalism and its "Prosperity Theology" represents the vocalization of a privatist ethos silently cultivated over decades of political and legal helplessness from the broader and vulnerable set of Brazilian society. This paper argues that neo-Pentecostalism emerged as the organizer of a political culture marked by the intersection of two current social processes, which are: 1) social change driven by the expansion of consumer society and 2) the lack of the capacitiy of the state, on the one hand, and of the civil society, on the other, to overcome the problems of social marginalization caused by excessive economic inequality and by the deficit of symbolic capital necessary to strengthen civic and democratic political culture.

Keywords: neo-Pentecostalism; political culture; democracy; peripheral modernity.

Recebido em 31 de janeiro de 2014.

Aprovado em 22 de maio de 2014. 